\title{
PENDAYAGUNAAN ARSIP FILM MELALUI KEGIATAN \\ PEMUTARAN FILM KERAGAMAN LOKAL KONTEN SEBAGAI PELESTARIAN NILAI SEJARAH DAN BUDAYA JAWA
}

\author{
Nurul Fadilla \\ Mahasiswa Pascasarjana Universitas Islam Negeri Sunan Kalijaga Yogyakarta \\ Konsentrasi Ilmu Perpustakaan dan Informasi \\ Nrlfdila@gmail.com \\ Sri Rohyanti Zulaikha \\ Dosen Pascasarjana Universitas Islam Negeri Sunan Kalijaga Yogyakarta \\ Konsentrasi Ilmu Perpustakaan dan Informasi \\ Yogya2102@gmail.com
}

\begin{abstract}
ABSTRAK
Penelitian ini bertujuan untuk mengetahui pendayagunaan arsip film melalui kegiatan pemutaran film keragaman lokal konten budaya Jawa DIY yang dilakukan oleh Grhatama Pustaka Balai Layanan Perpustakaan DPAD DIY. Penelitian ini menggunakan metode studi kasus dengan pendekatan kualitatif. Teknik pengumpulan data pada penelitian ini yaitu dengan cara observasi, wawancara, dan studi kepustakaan (library research). Dari hasil penelitian menunjukkan bahwa pendayagunaan arsip film melalui kegiatan pemutaran film keragaman lokal konten budaya Jawa DIY pada Grhatama Pustaka memberikan pengaruh positif dalam melestarikan nilai budaya dan sejarah melalui film, perkenalan budaya dan sejarah dilakukan dengan cara yang cukup berbeda yaitu dari adanya film dokumenter. Hal itu tercermin dari sikap dan perilaku pemustaka yang memberikan feedback secara langsung, baik dari segi film yang menambah wawasan, pengetahuan baru perihal budaya, sejarah serta pariwisata yang telah terjadi yang mungkin belum familiar bagi para pemustaka, dan adanya komentar terkait durasi film yang dirasa singkat sehingga menjadi ketertarikan tersendiri bagi pemustaka untuk ingin menonton film dokumenter lainnya serta statistik pengunjung yang menyaksikan pemutaran film dokumenter kian naik dan bertambah. Rekomendasi dari penelitian ini diharapkan lebih memperbanyak koleksi film dokumenter lainnya, sehingga film lama tidak hanya sekedar menjadi arsip saja tapi dapat didayagunakan kembali sehingga kebermanfaatannya terasa, dan diharapkan untuk lebih mempromosikan, memperkenalkan kegiatan pemutaran film, semakin memperluas jaringan kerjasama agar dapat menjalin hubungan dengan pihak-pihak tertentu terkait pemutaran film dokumenter, agar karya yang dihasilkan jangka waktu penggunaan atau pemanfaatannya dapat dirasakan lebih lama dan dijangkau oleh lebih banyak orang lagi terutama generasi berikutnya di masa depan.
\end{abstract}

Kata Kunci: Film Dokumenter, Sejarah, Budaya Jawa, Arsip Film. 


\section{PENDAHULUAN}

Sejak zaman penjajahan sampai dalam kehidupan di zaman seperti saat sekarang ini, istilah arsip telah memiliki persepsi tersendiri yang kian berbeda diantara individu yang satu dengan individu yang lain dalam pemaknaannya. Arsip telah menjadi salah satu sumber mutlak atas informasi yang memiliki kepentingan signifikan baik bagi individu maupun dalam kegiatan administratif di lembaga baik lembaga pemerintahan maupun lembaga swasta. Arsip bukanlah sekedar kumpulan kertas yang kumuh, yang sudah cukup berumur, dan berada di pojok ruangan, namun lebih dari itu. Arsip pada realitasnya dijadikan sebagai bahan informasi, bahan rujukan baik dalam proses perencanaan, penanggungjawaban sebuah hasil, pengambilan keputusan ataupun sebagai bukti otentik atas suatu informasi yang dihasilkan. Arsip senantiasa perlu disimpan karena memiliki fungsi dan manfaatnya tersendiri, beberapa diantaranya sebagai pusat ingatan, sumber informasi dan alat pengawasan bagi pimpinan baik itu di suatu lembaga atau organisasi (Mirmani 2014, 1.4). Sehingga patut disadari bahwa arsip memang diharuskan untuk dapat dilestarikan dan dikelola dengan baik agar terselamatkannya informasi yang terkandung di dalamnya sehingga dapat dipergunakan lagi bagi generasi berikutnya di masa depan.

Seiring metamorfosanya, selain berdasarkan bentuk dan jenisnya ternyata arsip juga dibedakan berdasarkan medianya, salah satunya adalah arsip media baru yaitu arsip film yang berasal dari arsip non tekstual atau disebut arsip citra bergerak (moving image) yang berisi informasi terekam dengan rangkaian gambar dan suara sebagai bahan dasar film dan pada saat proses pembuatannya memiliki prosedur berupa rancangan secara teknis dan artistik dengan menggunakan peralatan secara khusus.Dari proses pembuatan film dengan merujuk perkembangan teknologi seiring jaman, maka akan terlihat peristiwa yang terjadi berdasarkan jaman dan tahun serta kejadian yang terjadi pada suatu bangsa.

Selain itu, film juga merupakan salah satu bentuk cara penyampaian arsip dengan cara yang berbeda dimana konten yang terdapat didalamnya menampilkan perkembangan jaman yang berisi nilai budaya dan sejarah yang amat kental pada jaman dulunya. Bila merujuk pada proses film dokumenter tidak hanya berisi nilai budaya, sejarah namun juga wisata, keunikan dan khas dari suatu daerah yang akan ditampilkan. Selain itu film keragaman lokal konten budaya jawa DIY menjadi daya tarik tersendiri untuk terus mampu memperkenalkan dan menunjukkan berbagai keragaman budaya dan sejarah yang dimiliki, agar nantinya dapat menjadi memori di ingatan. Selain menjadi media pelestarian budaya dan sejarah, film juga menjadi media pembelajaran dan pengembangan pengetahuan bagi generasi-generasi muda di jaman seperti saat sekarang ini dan generasi berikutnya yang tidak tahu bagaimana sejarah dan budaya yang ada sebenarnya.

Apalagi jika melihat berbagai bentuk perkembangan jaman saat ini, salah satunya dengan masuknya budaya barat yang membuat nilai budaya dan sejarah kian luntur tergantikan budaya barat tersebut. Padahal sejatinya, sebagai warga negara yang baik kita harus bangga dan senantiasa menjaga serta melestarikan budaya yang dimiliki. Budaya yang dimiliki tersebut sering disebut dengan istilah lokal konten. Lokal konten merupakan suatu koleksi yang dihasilkan secara murni oleh bangsa dan negara kita sendiri dan untuk membuatnya lebih menarik maka disajikan dan dikemas dalam bentuk film.

Banyak cara yang dapat dilakukan untuk melestarikan budaya dan sejarah serta memperkenalkan wisata, keunikan dan keragama budaya jawa DIY salah satunya dengan 
mendayagunakan arsip film dengan menonton film dokumenter. Yang mana dari arsip film yang ada dapat menjangkau dan menyebarluaskan informasi yang terkandung di dalam film tersebut ke lebih banyak orang lagi terutama generasi muda sebagai generasi penerus bangsa.

\section{TINJAUAN PUSTAKA}

Arsip merupakan istilah dari bahasa Belanda yaitu Archief. Archief sendiri berasal dari kata Archeion yaitu bahasa Yunani dan Archivum yaitu bahasa Latin. Dari berbagai istilah tampaknya Indonesia menyerap istilah tersebut dari Belanda dikarenakan mulanya lembaga kearsipan Indonesia didirikan oleh Pemerintah Hindia Belanda (Sulistyo-Basuki 2017, 7).

Menurut Undang-Undang Republik Indonesia Nomor 43 Tahun 2009 Tentang Kearsipan, Pasal 1, Ayat 2, Arsip adalah rekaman kegiatan atau peristiwa dalam berbagai bentuk dan media sesuai dengan perkembangan teknologi informasi dan komunikasi yang dibuat dan diterima oleh lembaga negara, pemerintahan daerah, lembaga pendidikan, perusahaan, organisasi politik, organisasi kemasyarakatan, dan perseorangan dalam pelaksanaan kehidupan bermasyarakat, berbangsa, dan bernegara.

Menurut The Council of Europe's sebagaimana yang dikutip oleh Ivan Azekely $(2017,4)$ mendefinisikan pengertian arsip yaitu sebagai berikut:"The word 'archives' has the following meanings: (i) when it is written with a lower case a: the totality of the documents produced or received by any individual or corporate body during the course of their business and transmitted to the Archives for permanent preservation. (ii) when it is written with an upper case a: the public institutions charged with the preservation of archives."

Dalam dunia pendidikan, menurut Burcak $(2013,109)$ arsip adalah "Archives are institutions in which materials which have to be stored over a long period of time are maintained and brought into use. The archival material has administrative, financial, judical, and more over, historical value”. Sedangkan, menurut Rob Fisher $(2009,6)$ arsip adalah "Private archives generally are defined as records created by individuals and corporate entities (including non-profit organization) outside of the public sphere of governments, governmenyal agencies, and departments".

Pada dasarnya arsip tidaklah muncul secara tiba-tiba, arsip telah mengalami perubahan secara perlahan-lahan, arsip juga memiliki karakteristik seperti merupakan informasi yang terekam, memiliki media yang nyata dan memiliki fungsi dan kegiatan.Arsip Nasional Republik Indonesia atau disingkat ANRI $(1999,5)$ telah membagi arsip berdasarkan bentuk dan medianya yaitu 1) arsip berbentuk kertas yaitu berupa data, gambar dan teks yang disimpan seperti yang banyak dijumpai, 2) arsip berbentuk film yaitu berupa data, gambar, rekaman, teks yang disimpan dalam film dan termasuk microfilm, 3) arsip media magnetik yaitu berupa data, gambar, teks yang disimpan dan ditemukan kembali dengan cara berupa penulisan kode secara magnetik dan khusus dengan adanya teknologi komputer.

Dalam Undang-Undang Republik Indonesia Nomor 43 Tahun 2009 Tentang Kearsipan, juga dijelaskan beberapa bentuk arsip seperti arsip dinamis, arsip vital, arsip aktif, arsip inaktif, arsip statis, dan arsip terjaga. Dalam metamorfosanya, menurut Suhardi dan Daryan $(1998,15)$ arsip juga dibedakan berdasarkan medianya yaitu sebagai berikut: 
1. Arsip tekstual adalah arsip konvensional berupa informasi terekam dengan media kertas atau teks yang dibaca tanpa adanya bantuan mesin.

2. Arsip pandang dengar dikenal dengan arsip audiovisual berupa arsip dalam bentuk gambar, suara, dengan apapun bentuk dan coraknya, yang dapat dilihat dan didengar, termasuk teks pelengkap didalamnya. Arsip pandang dengar juga dibedakan berdasarkan perangkat teknologi saat proses penciptaanya, yaitu:

a. Gambar statik (still image) yaitu arsip yang memiliki isi informasi berupa citra diam, contohnya foto dan slide.

b. Citra bergerak (moving images) yaitu arsip yang memiliki isi informasi berupa citra bergerak, contohnya film dan video.

c. Rekaman suara (sound recording) yaitu arsip yang memiliki isi informasi terekam dalam sinyal suara dengan menggunakan sistem perekam, contohnyya kaset.

3. Arsip kartografik dikenal dengan kearsitekturan kartografik berupa arsip yang berisi informasi dalam bentuk gambar grafis, fotogrametrik perihal muka bumi ataupun sistem galaksi yang disusun berdasarkan skala-skala tertentu, contohnya peta dan bagan.

4. Arsip gambar teknik dikenal dengan kearsitekturan berupa arsip gambar rancang bangun, contohnya gedung dan jembatan.

5. Arsip komputer berupa arsip yang berisi informasi yang dihasilkan dengan menggunakan komputer yang direkam dalam media magnetik ataupun media optical, contohnya hard disk, floopy disk, dan CD ROM.

Sebagai salah satu contoh dari arsip pandang dengar atau arsip audiovisual, arsip film merupakan bentuk dari citra bergerak yang mana isi informasinya terekam dalam rangkaian gambar dan memiliki suara sebagai bahan dasar film, yang mana pada proses pembuatannya memiliki prosedur berupa rancangan secara teknis dan artistik dengan menggunakan peralatan secara khusus.Dari proses pembuatan film dengan merujuk perkembangan teknologi seiring jaman maka akan terlihat peristiwa yang terjadi berdasarkan jaman dan tahun serta kejadian yang terjadi pada suatu bangsa.

Menurut Undang-Undang Nomor 8 Tahun 1992 Tentang Perfilman, Film adalah karya cipta seni dan budaya yang merupakan media komunikasi massa pandang-dengar yang dibuat berdasarkan atas sinematografi dengan direkam pada pita seluloid, pita video, piringan video, dan atau bahan hasil penemuan teknologi lainnya dalam segala bentuk, jenis, dan ukuran melalui proses kimiawi, proses elektronik, atau proses lainnya, dengan atau tanpa suara, yang dapat dipertunjukkan dan/atau ditayangkan dengan system proyeksi mekanik, elektronik, dan/atau lainnya.Setelah itu tepat tahun 2009, dikeluarkan UU baru mencabut UU lama perihal perfilman yaitu Undang-Undang Nomor 8 Tahun 1992 Tentang Perfilman, tdan digantikan pada Undang-Undang Nomor 33 Tahun 2009 yang menyatakan bahwa Film adalah karya seni budaya yang merupakan pranata sosial dan media komunikasi massa yang dibuat berdasarkan kaidah sinematografi dengan atau tanpa suara dan dapat dipertunjukkan.Pengertian tersebut secara signifikan lebih sederhana dan jelas, film dikatakan sebagai karya seni budaya yang memiliki peran strategis dalam peningkatan ketahanan 
budaya bangsa dan kesejahteraan masyarakat lahir batin untuk memperkuat ketahanan nasional.

Bila ingin merealisasikan peningkatan ketahanan budaya bangsa maka film dokumenter menjadi salah satu bentuk film yang tepat. Dalam Kamus Besar Bahasa Indonesia (2008, 316) Film dokumenter adalah suatu dokumentasi dalam bentuk film mengenai suatu peristiwa bersejarah atau suatu aspek seni budaya yang mempunyai makna khusus agar dapat menjadi alat penerangan dan alat pendidikan.Film dokumenter juga merupakan film yang berisikan fakta atau peristiwa yang terjadi, dimana pembuatannya memerlukan pemikiran dan perencanaan yang matang (Effendy 2000, 214).

Pendapat lain menurut Patricia Aufderheide $(2007,2)$ perihal pemaknaan film dokumenter yaitu "A movie about real life. And that is precisely the problem, documentaries are about real life, they are not real life. They are not even windows onto real life. They are portraits of real life, using real life as their raw material, constructed by artists and technicians who make myriad decisions about story to tell to whom, and for what purpose." Definisi ini menyatakan bahwa film dokumenter adalah sebuah film yang menceritakan kehidupan nyata. Bahkan film dokumenter tidak menayangkan kehidupan nyata melinkan potret dari kehidupan nyatanya. Film dokumenter menggunakan kehidupan nyata sebagai bahan untuk membuat film, lalu diolah menjadi sebuah cerita oleh sineas dan diperankan oleh artis dengan penyesuaian target penonton dan tujuan dari proses pembuatan.

\section{Keragaman Lokal Konten}

Konten lokal merupakan suatu program yang diperoduksi dibawah pengontrolan kreatif dari warga asli setempat, yang mana terdiri dari fiksi, film seri, film dokumenter, program seni, acara pendidikan dan lainnya yang merupakan karya asli dari dalam negeri. Sedangkan, menurut Khan dari UNESCO yang dikutip oleh Christiany (2015, 53) mendefinisikan bahwa konten lokal adalah sebuah bentuk ekspresi dan komunikasi dari masyarakat yang dihasilkan secara lokal, yang mana dapat diartikan bahwa apa yang dimiliki masyarakat baik berupa pengetahuan ataupun pengalaman kemudian diadaptasi dan berhubungan dengan situasi masyarakat setempat.

Budaya lokal sering disebut juga dengan kearifan lokal. Kearifan lokal dikenal dengan istilah local wisdom. Menurut J. Habba $(2007,7)$ dalam kearifan lokal terdapat tiga kategori utama yaitu sebagai berikut:

1. Superculture, yaitu kebudayaan yang berlaku bagi seluruh masyarakat atau kebudayaan nasional.

2. Culture, yaitu kebudayaan yang lebih khusus berdasarkan golongan etnik, profesi wilayah atau daerah seperti halnya budaya Sunda, Minang, Batak, dan lainnya.

3. Subculture, yaitu kebudayaan khusus dalam sebuah culture, akan tetapi kebudayaan ini tidaklah bertentangan dengan kebudayaan yang mana merupakan bagian turunan dari culture, namun counter-culture inilah yang bertentangan dengan kebudayaan induknya (budaya individualism).

\section{METODE PENELITIAN}

Penelitian ini dilakukan menggunakan metode studi kasus dengan pendekatan gabungan yaitu kualitatif dan kuantitatif. Pengambilan sampel dilakukan dengan menggunakan teknik purposive agar dapat memilih secara langsung sumber data berdasarkan 
tujuan yang ingin dicapai. Sampel dalam penelitian ini sebanyak 4 orang. Sampel merupakan orang-orang yang dipilih sebagai informan yang benar-benar telah mendayagunakan arsip film melalui kegiatan pemutaran film keragaman lokal konten pada Balai Layanan Perpustakaan DIY, yaitu dan Mba Aida (Informan I) merupakan salah satu dari orang tua yang tampak hadir menemani anaknya serta ikut menyaksikan pemutaran arsip film dokumenter. Fenita (Informan II) seorang mahasiswa di salah satu Universitas di Yogyakarta. Rasya (Informan II) seorang pelajar di salah satu SD di DIY. Dan Mas Kharisma (Informan I) adalah petugas operator pada layanan audio visual Grhatama Pustaka Balai Layanan Perpustakaan DPAD DIY.

Metode studi kasus yaitu suatu metode dengan memusatkan diri secara intensif pada satu obyek tertentu yang mempelajarinya sebagai suatu kasus. Data studi kasus dapat diperoleh dari semua pihak yang bersangkutan, dan dengan kata lain dalam studi ini dikumpulkan dari berbagai sumber. Studi kasus yang baik harus dilakukan secara langsung dalam kehidupan sebenar-benarnya dari kasus apa yang diselidiki. Namun, data studi kasus dapat diperoleh tidak saja dari kasus yang diteliti akan tetapi juga dapat diperoleh dari semua pihak yang mengetahui dan mengenal kasus tersebut dengan baik sehingga dapat diperoleh dari berbagai sumber namun terbatas dalam kasus yang akan diteliti (Hadari 2003, 9).

Sedangkan pendekatan kualitatif menurut J.W. Creswell (1994, 140)akan menjelaskan apa yang didapatkan peneliti dari hasil observasi dan penyelidikan untuk dapat memahami permasalahan berdasarkan latar alamiahnya. Pendekatan kualitatif juga akan memberikan asumsi bahwa penekanan perhatian ada pada proses bukannya pada hasil atau produk, dengan keterlibatan peneliti dalam kerja lapangan membuat peneliti berinteraksi dengan orang, latar, lokasi atau mencatat perilaku dalam latar yang alamiah.

Teknik pengumpulan data pada penelitian ini yaitu dengan cara observasi langsung, wawancara secara mendalam, dan studi kepustakaan (library research). Observasi merupakan suatu kegiatan mencari data yang diperlukan agar dapat digunakan untuk menarik suatu kesimpulan dan diagnosis (Herdiansyah 2012, 131).Observasi dilakukan untuk melihat dan mengamati proses pendayagunaan dengan ikut menyaksikan pemutaran arsip film dokumenter secara langsung dan mendapatkan gambaran langsung mengenai kondisi serta upaya yang dilakukan dalam proses pemutaran arsip film dokumenter pada layanan audio visual Grhatama Pustaka Balai Layanan Perpustakaan DPAD DIY.

\section{PEMBAHASAN}

\section{Arsip Film Dokumenter Lokal Konten Budaya Jawa Pada Layanan Audiovisual Grhatama Pustaka Balai Layanan Perpustakaan DPAD DIY}

Film dokumenter mendeskripsikan kenyataan-kenyataan secara objektif sebagai bahan utamanya. Film dokumenter lokal konten yang dipertunjukkan oleh Layanan Audiovisual Grhatama Pustaka Balai Layanan Perpustakaan DPAD DIY merupakan bentuk lokal konten yang menampilkan kearifan lokal budaya jawa yang ada di DIY, yaitu budaya lokal masyarakat setempat, baik dari ujung timur, utara, barat sampai selatan DIY.

Membahas budaya Jawa terutama pada Daerah Istimewa Yogyakarta seperti tidak akan pernah ada habisnya, mulai dari keragaman budaya, kesenian, kekhasannya, sejarahnya, kebiasaannya, adat istiadatnya, para leluhurnya, objek wisatanya, kuliner khasnya, dan lain 
sebagainya, kesemuanya tersebut terangkum dalam film dokumenter yang dimiliki oleh Grhatama Pustaka Balai Layanan Perpustakaan DPAD DIY. Setiap film yang dimiliki memiliki nilai-nilai sejarah didalamnya, sehingga dapat dikatakan bahwa informasi yang terkandung di dalam arsip film mempunyai arti yang signifikan penting. Karena adanya arti yang signifikan tersebutlah maka penyampaian informasi arsip film koleksi Grhatama Pustaka Balai Layanan Perpustakaan DPAD DIY terus dilakukan dengan adanya kegiatan rutin yang dilakukan pada layanan audiovisual melalui pendayagunaan arsip film.

Layanan audiovisual secara rutin dan telah terjadwal untuk menggelar kegiatan pemutaran film dokumenter yang berisi keragaman lokal konten DIY. Adapun lokasi Grhatama Pustaka Balai Layanan Perpustakaan DPAD DIY tepatnya di Jalan Janti, Banguntapan, Bantul, Yogyakarta. Sebenarnya jika ditelusur secara lebih dalam, informasi perihal layanan audiovisual dengan menampilkan arsip film belum banyak diketahui oleh masyarakat secara luas. Padahal jika di telaah, nilai edukasi, sejarah dan budaya yang terdapat dalam pemutaran film dokumenter terhadap para pemustaka sangat bermanfaat dan memiliki dampak yang positif. Berdasarkan hal tersebut maka penulis melakukan wawancara terhadap beberapa informan yang telah mengetahui dan menyaksikan secara langsung arsip film dokumenter koleksi dari Balai Layanan Perpustakaan DPAD DIY.

Dari hasil wawancara secara langsung menunjukkan bahwa para informan yang telah mengetahui dan menyaksikan secara langsung arsip film dokumenter mendapatkan informasi dari media sosial yang diikuti yaitu instagram.com/@balaiyanpus.dpaddiy, selain itu adanya berbagi informasi antara sesama teman juga terjadi baik itu pada kalangan pelajar, mahasiswa, guru dan orang tua yang sebelumnya sudah pernah berkunjung sehingga menjadi jembatan penghubung adanya sharing information perihal terlaksananya kegiatan pemutaran arsip film dokumenter. Dan yang terakhir dari adanya informasi atau pemberitahuan yang senantiasa disampaikan secara langsung perihal jadwal dan film yang akan diputar melalui speaker penghubung yang dapat didengar oleh semua pemustaka yang berada di tiap lantai, dan ini terus menerus dilakukan sampai jadwal film mendekati \pm 10 menit terakhir. Hal ini menjadi salah satu cara yang cukup baik mengingat tidak semua pemustaka mengetahui adanya kegiatan pemutaran arsip film, namun setelah pemberitahuan tersebut tidak jarang menjadi ketertarikan tersendiri bagi pemustaka yang awalnya hanya datang ke perpustakaan untuk mendayagunakan koleksi buku-buku dan internet tapi kini ikut serta mendayagunakan arsip film melalui kegiatan pemutaran film dokumenter.

Pendayagunaan arsip film melalui kegiatan pemutaran film keragaman lokal konten ini telah terlaksana sejak tahun 2016, dan sampai saat ini ada sekitar \pm 70 (tujuh puluh) film dokumenter yang menjadi arsip dan bersumber dari adanya kerjasama dengan Dinas Kebudayaan Daerah Istimewa Yogyakarta. Salah satu arsip film dokumenter yang diputar yaitu “Ayo Ke Kulon Progo”, tepatnya pada hari Sabtu, 29 Februari 2020.

Film Ayo Ke Kulon Progo menjadi salah satu dari sekian arsip film dokumenter yang berisi nilai sejarah dan budaya. Dari hasil wawancara dengan para informan diketahui bahwa, sebelumnya Informan I yaitu sebagai warga asli Yogyakarta yang sama sekali belum pernah ke Kulon Progo menjadi tertarik untuk segera datang kesana melihat secara langsung budaya yang telah ditampilkan dalam film juga senang dengan respon yang diberikan oleh anaknya setelah menonton film dokumenter tersebut. Baginya film tersebut tidak hanya menampilkan segi budaya saja namun juga memberikan nilai edukasi dan sejarah yang baik bagi 
perkembangan pengetahuan sang anak, dimana anak di jaman seperti sekarang ini telah banyak mendapat film-film yang terlampau jauh dari usia mereka.

Selaras denganinforman I, Informan II mengatakan bahwa ia adalah seorang mahasiswa di salah satu Universitas di Yogyakarta. Dia merupakan pendatang dari kota lain merasa bahwa pemutaran arsip film menjadi sangat layak untuk jadi kegiatan rutinnya saat berkunjung ke Balai Layanan Perpustakaan DPAD DIY, ia yang awalnya hanya datang untuk mendayagunakan koleksi buku dan internet, kini rutin menyaksikan pemutaran arsip film dokumenter. Baginya pemutaran arsip film mengajarkan nilai-nilai sejarah yang sebelumnya tidak ia ketahui, membuka cakrawala dan pemikirannya yang awalnya hanya terbatas kini menjadi lebih luas lagi dari sebelumnya. Tidak hanya itu kegiatan pemutaran film dokumenter menjadi aktivitas baru baginya yang memberi manfaat positif daripada hanya sekedar berjalan-jalan di mall atau duduk-duduk di cafe bersama temannya.

Informan III mengatakan bahwa ia adalah seorang pelajar atau siswa disalah satu Sekolah Dasar (SD), ia berkunjung untuk menyaksikan pemutaran arsip film dokumenter, biasanya ia datang bersama teman-teman dan orangtuanya di waktu weekend, yaitu hari Sabtu dan Minggu. Informan II sendiri merupakan salah satu anak yang menjadi penonton setia, dan merasa bahagia mendapat tempat rekreasi dan sumber pengetahuan baru dari pemutaran arsip film, tak hanya Informan II orang tuanya pun juga ikut bahagia karena selain mendapat tempat rekreasi yang bermanfaat, film yang memiliki dampak dan pelajaran yang positif, tapi juga tidak adanya biaya yang perlu dikeluarkan untuk ikut serta menyaksikan film dokumenter tersebut (gratis). Setelah pulang menyaksikan film dokumenter, ia selalu menceritakan pengalaman dan isi film tersebut kepada orangtua dan teman-temannya, sehingga tak jarang di kemudian hari teman-temannya tertarik dan ikut serta bersamanya untuk diajak menyaksikan film dokumenter di Balai Layanan DPAD DIY.

Informan IV, telah cukup lama berkecimpung dalam kegiatan pemutaran arsip film dokumenter pada Balai Layanan Perpustakaan DPAD DIY, yaitu sejak tahun 2017. Ia mengatakan bahwa pemustaka yang awalnya berkunjung untuk memanfaatkan koleksi, juga ikut serta menyaksikan film dokumenter. Pada waktu weekend tiba yaitu Sabtu dan Minggu, cukup banyak orangtua bersama anaknya datang secara khusus hanya untuk menonton film dokumenter yang ditampilkan. Dari statistik dan daftar hadir pengunjung pun terlihat bahwa terjadi kenaikan setiap waktu weekend tiba.

Arsip film dokumenter secara tidak langsung melakukan sharing information dan sharing knowledge of culture DIY. Informasi yang terdapat di dalam film ditujukan kepada seluruh golongan masyarakat baik untuk anak-anak, remaja, mahasiswa, dan orangtua. Tujuan penyampaian informasi tersebut diharapkan masyarakat dapat mengetahui nilai budaya dan sejarah yang terdapat di berbagai sudut dari Kota Jogja untuk menambah wawasan dan pengetahuan mulai dari keragaman seni, sejarah, kekhasan, kebiasaan, adat istiadat, para leluhur, objek wisata, kuliner khas, dan lain sebagainya. Cerita mengenai sejarah memang cukup banyak bertebaran baik dari cuplikan film pada umumnya, buku pelajaran sosial maupun buku cerita, namun tidak ada yang secara detail menjelaskan dan menggambarkannya seperti halnya yang terdapat pada arsip film dokumenter milik Balai Layanan Perpustakaan DPAD DIY ini.

Kuatnya arus globalisasi serta masuknya budaya barat ke Indonesia mengikis nilai sejarah dan budaya di berbagai kalangan terutama generasi muda saat ini. Terkikis dan 
lunturnya pengetahuan perihal nilai sejarah dan budaya akan berdampak buruk bagi bangsa dan negara. Untuk di Jawa sendiri, terdapat begitu banyak sejarah dan budaya yang harus dan senantiasa dilestarikan, saat ini seluruh lini kehidupan harusnya paham akan nilai sejarah dan budaya yang begitu penting agar kedepannya dapat terus dirasakan, digunakan, dijalankan, diberdayakan. Namun tak jarang sebagian kalangan merasa kurang tertarik bila hanya mendapatkan informasi perihal nilai sejarah dan budaya hanya dari media tekstual.

Balai Layanan Perpustakaan DPAD DIY menjawab pertanyaan atas ketidaktertarikan tersebut dengan menyajikan pemutaran film keragaman sejarah dan budaya Jawa melalui pendayagunaan arsip film dokumenter yang dimiliki. Film dokumenter dikemas dengan baik dan disajikan dengan baik pula melalui layanan audiovisual dengan tempat dan ruangan yang nyaman. Tak hanya itu, film yang ditampilkan juga selalu memberikan nilai sejarah, budaya, serta pengaruh positif di dalamnya seperti edukasi dan informasi. Selain itu, Balai Layanan Perpustakaan DPAD DIY juga ingin menjadikan layanan audiovisual sebagai salah satu tempat rekreasi rujukan tanpa adanya pungutan biaya yang dibebankan, juga secara tidak langsung ikut serta menampilkan keindahan alam dan pariwisata yang dimiliki. Dengan media film penyampaian-penyampaian hal positif yang ingin disampaikan dasarnya relatif lebih mudah tersampaikan dan diterima oleh penonton yang menyaksikan. Selain itu film dokumenter yang disajikan juga dapat ditonton oleh seluruh kalangan tanpa adanya batasan umur, jenis kelamin, ras atau lainnya.

\section{PENUTUP}

\section{Kesimpulan}

Hasil penelitian menunjukkan bahwa pendayagunaan arsip film melalui kegiatan pemutaran film keragaman lokal konten budaya Jawa pada Grhatama Pustaka Balai Layanan Perpustakaan DPAD DIY memberikan pengaruh positif dalam melestarikan nilai budaya dan sejarah melalui film. Perkenalan budaya dan sejarah dilakukan dengan cara yang cukup berbeda yaitu dari adanya film dokumenter.

\section{Saran}

Dari kesimpulan, selanjutnya ditarik beberapa saran dan rekomendasi untuk kemajuan yang lebih baik yaitu sebagai berikut:

1. Koleksi film dokumenter lainnya, sehingga film-film lama tidak hanya sekedar menjadi arsip saja tapi dapat didayagunakan kembali sehingga kebermanfaatannya terasa

2. Lebih mempromosikan dan memperkenalkan kegiatan pemutaran arsip film dokumenter agar lebih dikenal masyarakat secara luas.

3. Memperluas jaringan kerjasama agar dapat menjalin hubungan dengan pihak-pihak tertentu terkait pemutaran film dokumenter, agar karya yang dihasilkan jangka waktu penggunaan atau pemanfaatannya dapat dirasakan lebih lama dan dijangkau oleh lebih banyak orang lagi terutama generasi berikutnya di masa depan. 


\section{DAFTAR PUSTAKA}

Arsip Nasional Republik Indonesia (ANRI). (1999). Modul Manajemen Arsip Dinamis. Jakarta: ANRI.

Aufderheide, Patricia. (2007). Documentary Film: A Very Short Introduction. New York: Oxford University Press.

Creswell, J.W. (1994). Research Design Qualitative and Quantitative. Jakarta: Raka Grafindo Press.

Departemen Pendidikan Nasional. (2008). Kamus Besar Bahasa Indonesia Pusat Bahasa. Jakarta: Gramedia Pustaka Utama.

Effendy, Onong Uchjana. (2000). Ilmu, Teori dan Filsafat Komunikasi. Bandung: Citra Aditya Bakti.

Fisher, Rob. (2009). In Search of a Theory Of Private Archives: The Foundational Writings

Of Jenkinson And Schellenberg Revisited. Archivaria: The Journal Of The Association of Canadian Archivists.

Habba, J. (2007). Analisis SWOT Revitalisasi Kearifan Lokal Dalam Studi Resolusi Konflik di Kalimantan Barat, Maluku dan Poso. Jakarta: ICIP.

Hadari, Nawawi. (2003). Metode Penelitian Bidang Sosial. Yogyakarta: UGM Press.

Herdiansyah, Haris. (2012). Metodelogi Penelitian Kualitatif Untuk Ilmu-Ilmu Sosial. Jakarta: Salemba Humanika.

Indonesia. Undang-Undang Republik Indonesia Nomor 43 Tahun 2009 Tentang Kearsipan.

Indonesia. Undang-Undang Nomor 8 Tahun 1992 Tentang Perfilman.

Indonesia. Undang-Undang Nomor 33 Tahun 2009 Tentang Perfilman.

Juditha, Christiany. (2015). Televisi Lokal dan Konten Kearifan Lokal: Studi Kasus Di Sindo TV Kendari. Jurnal Penelitian Komunikasi dan Pembangunan. Vol. 16, No. 1, Juni.

Mirmani, Anom. (2014). Pengawasan Kearsipan. Tangerang: Universitas Terbuka.

Senturk, Burcak. (2013). The Use Of Archives In Education" Examples From Abroad. International Journal on New Trends in Education and Their Implications. Vol. 4, Issue 1, January.

Suhardi, Hardi dan Yayan Daryan. (1998). Terminologi Kearsipan Indonesia. Jakarta: Sigma Cipta Utama.

Sulistyo-Basuki. (2017). Pengantar Kearsipan. Papua: Aseni.

Szekely, Ivan. (2017). Do Archives Have A Future in The Digital Age? Journal of Contemporary Archival Studies. Vol. 4. 